THURSDAY, MAY ${ }_{55}$, IS73

\section{A VOICE FROM CAMBRIDGE}

II.

$7^{\top H E}$ questions raised by the Cambridge Memorial to 1 which we referred last week are so important that no excuse is necessary for recurring to them. In the first place it may be remarked that the answer of Mrr. Gladstone to the Cambridge memorialists, is quite such as any reasonable man might have looked for. University rcform is not at present a political question in the vulgar sense of that word. The heart of the masses is not stirred by proposals concerning the tenure of fellowships. The religious element, or rather the sectarian element, has now been largely eliminated from the matter; there remains scarcely anything at stake save the intercsts of learning and science; and these, as wc know, are things of very little value in the cyes of the present Government.

The more one looks at the matter the more it is difficult to see what good the Cambridge Reformers expected to result from their respectable document. No fault can be found with the propositions of the memorial so far as they go. They are just such sound steady.going sober proposals as would naturally come from a body of quiet moderate officials who, on the whole, content with the general state of things, desired to see some practical amendments introduced, but dreaded to agitate, had a wholesome fear of radical changes, and above all, were not clear about the broad features of the necessities which have to be met, or of the changes which have to be brought about.

Until the public mind, to say nothing of the University mind, has gained some clear definite notions about the functions of a University, all attempts at reform must be partial or complete failures.

The prevalent theories concerning the office of a University may be put in three categories.

The first regards the University as an ecclesiastical nursery. This was the original view, but novi-a-days is passing out of mind, though tenaciously clung to by some resident members at either University. It only needs to be mentioned to be dismissed.

The second looks upon Oxford and Cambridge as places where the young Tartars of modern English society are covered with a varnish of "culture," and polished into gentlemen. Dr. Lyon Playfair said in the House the other day that the Scotch University taught a man how to make a thousand a year, the English University how to spend it; and in saying this he simply put into forcible language the ideas which are prevalent among many members of the Universities. They distinctly and emphatically discard the idea that it is the duty of the University to equip a man for the struggle for a livelihood, to train him for business, for the arts, for the professions. Their token is "culture," not culture in the sense of higher learning, but in the sense of personal varnish, in the sense of a mental equipment which does not pay, and which is of no use to the owner in practical life, which is a luxury and not a need, a sort of evening dress of the mind, which may be ornamental under the artificial lights No. $185-$ Vor. virt. of society, but is ill suited for every-day work. Now this sort of culture is not much sought after; for by hard. headed fathers whose sons have to get or to keep their living by their own exertions, it is sought for less and less year by year. The advocates of the view we are dealing with see this very clearly, and accordingly they contend, very. logically, that since the world does not care greatly for this kind of culture, and will not send its sons to a University for that only, some other inducements must be provided. And these are found in the prize fellowships, more especially in the non-resident fellowships. A lad of parts whose friends would not send him to Oxford simply to gain that liberal education, "which softens the character and prevents its being strong," goes there because by show of possessing that culture which he despises or even hates, he gains a good round sum of money which it is worth his while to waste three or four years in getting.

The third view, which at present has but few advocates, teaches that the University is a place where anyone and everyone may be trained for any and every respectable path of life, and where at the same time all the interests of higher learning and science are cared for. The advo. cates of this view say, Do not bribe men by fellowships to come to a University from which they will go carrying with them a very little learning, and that for the most part useless, and an artificial culture of doubtful value. Make it worth their while to come to the University, teach them there what they want to be taught, train them there as they desire to be trained, and there will be no need to bribe them with fellowships. They will then come to Oxford and to Cambridge as they are now going to Owens College, to London, to Newcastle, and to Germany. Take care at the same time that the teaching be not narrow and professional, broaden it with the diligent nurture of higher learning and science, and then there will be every hope of seeing true culture and useful education going hand in hand. Let the youth of the University have the opportunity of seeing the masterminds of the age at their work, so that they may be inspired by them to the highest reaches of thought.

It appears to us that many of those who signed the Cambridge memorial had no clear ideas as to which of the above views they adhered; and hence the uncertain sound of their trumpet. Apparently the document was so loose that supporters of all three views signed it conscientiously; no wonder it fell without effect.

It is unnecessary for us to say that the third view we have mentioned is one which we ourselves support. The real difficulty lies in this, how to change the old Universities to suit these new views, how to ring out the old ecclesiasticism and false culture and ring in useful training with high science and deep active learning and research. The difficulty of this task cannot be exaggerated. Long years of misrule have left suckers of jobbery, like bindweed in an old garden, which come up refreshed with every stirring of the soil. There is a mass of powerful conservatism which has to be striven against. - There is a careless public and a still more careless Government which has to be roused. There are plenty of difficulties in the way. If the memorialists really have the reform of the old universities at heart, they will cease to memorialise feebly a feeble administration, and search dili- 
gently for some broad scheme of reform which may be introduced without danger, which will render all fellowships unnecessary, which will at once provide for the professional student and the original investigator, and that in such a way that an ignorant Parliament shall have no excuse for tampering with it. And if they do this quickly, they may do it before the Association for Academical Organisation has begun to stretch its limbs.

\section{LONGMANS' TEXT.BOOKS OF SCIENCE}

Electricity and Magnetism. By Fleeming Jenkin, F.R.SS. L. and E., M.I.C.E., Professor of Engineering in the University of Edinburgh. (London : Longmans and Co., 1873.)

THE author of this text-book tells us with great truth electricity-one that of the lecture-room and the popular treatise; the other that of the testing-office and the engineer's specification. The first deals with sparks and shocks which are seen and felt, the other with currents and resistances to be measured and calculated. The popularity of the one science depends on human curiosity; the diffusion of the other is a result of the demand for clectricians as telegraph engineers.

The text-book before us, which is the work of an engineer eminent in telegraphy, is designed to teach the practical science of electricity and magnctism, by setting before the student as early as possible the measurable quantities of the science, and giving him complete instructions for actually measuring them.

"The difference between the electricity of the schools and of the testing office has been mainly brought about by the absolute necessity in practice for definite measurement. The lecturer is content to say, under such and such circumstances, a current flows or a resistance is increased. The practical electrician must know how much resistance, or he knows nothing; the difference is analogous to that between quantitative and qualitative analysis."

It is not without great effort that a science can pass out of one stage of its existence into another. To abandon one hypothesis in order to embrace another is comparatively easy, but to surrender our belief in a mysterious agent, making itself visible in brilliant experiments, and probably capable of accounting for whatever cannot be otherwise explained; and to accept the notion of electricity as a measurable commodity, which may be supplied at a potential of so many Volts at so much a Farad, is a transformation not to be effected without a pang.

It is true that in the last century Henry Cavendish led the way in the science of electrical measurement, and Coulomb invented experimental methods of great precision. But these were men whose scientific ardour far surpassed that of ordinary mortals, and for a long time their results remained dormant on the shelves of libraries. Then came Poisson and the mathematicians, who raised the science of electricity to a height of analytical splendour, where it was even more inaccessible than before to the uninitiated.

And now that electrical knowledge has acquired a commercial value, and must be supplied to the telegraphic world in whatever form it can be obtained, we are perhaps in some danger of forgetting the debt we owe to those mathematicians who, from the mass of their unin. terpretable symbolical expressions, picked out such terms as "potential," "electromotive force" and "capacity," representing qualities which we now know to be capable of direct measurement, and which we are beginning to be able to explain to persons not trained in high mathematics.

Prof. Jenkin has, we think, made great progress in the important work of reducing the cardinal conceptions of electromagnetism to their most intelligible form, and presenting them to the student in their true connection.

The distinction between free electricity and latent, bound, combined, or dissimulated electricity, which occurs so frequently, especially in continental works on electricity, is not, so far as we can see, even alluded to in these pages; so that the student who takes Prof. Jenkin as his sole guide will not have his mind infected with a set of notions which did much harm in their day. On the other hand, terms which are really scientific-the use of which has led to a clearer understanding of the subject-are carefully defined and rendered familiar by well-chosen illustrations.

Thus we find that men of the most profound scientific acquirements were labouring forty years ago to discover the relation between the nature of a wire and the strength of the current induced in it. By the introduction of the term "electromotive force" to denote that which produces or tends to produce a current, the phenomena can now be explained to the mere beginner by saying that the clectromotive force is determined by the alterations of the state of the circuit in the field, and is independent of the nature of the wire, while the current produced is measured by the electromotive force divided by the resistance of the circuit. To impress on the mind of the student terms which lead him in the right track, and to keep out of his sight those which have only led our predecessors, if not ourselves, astray, is an aim which Prof. Jenkin seems to have kept always in view.

To the critical student of text-books in general, there may appear to be a certain want of order and method in the first part of this treatise, the different facts being all thrown into the student's mind at once, to be defined and arranged in the chapters which follow. But when we consider the multiplicity of the connexions among the parts of electrical science, and the supreme importance of never losing sight of electrical science as a whole, while engaged in the study of each of its branches, we shall see that this little book, though it may appear at first a mighty maze, is not without a plan, and though it may be difficult to determine in which chapter we are to look for any particular statement, we have an excellent index at the end to which we may refer.

The descriptions of scientific and telegraphic instruments have all the completeness and more than the conciseness which we should look for from a practical engineer, and in a small compass contain a great deal not to be found in other books. The preface contains an outline of the whole subject, traced in a style so vigorous, that we feel convinced that the author could, with a little pains bestowed here and there, increase the force of his rcasoning by seyeral "Volts," and at the same time diminish by" 